\title{
Estimation of Basic Reproduction Number for Dengue Fever in Lahore, Pakistan
} (Penganggaran Asas Nombor Pembiakan $R_{0}$ untuk Demam Denggi di Lahore, Pakistan)

\author{
NOOR BADSHAH *, HASSAN SHAH \& MUHAMMAD JAVID
}

\begin{abstract}
Dengue fever is a vector-borne viral disease which is now endemic in more than 100 countries affecting more than 2.5 billion people worldwide. In recent years, dengue fever has become a major threat to public health in Pakistan. In this paper, we derived an explicit formula for reproduction number $R_{0}$ (the most important epidemiological parameter) and then used real data of dengue fever cases of different hospitals of Lahore (Pakistan) on $R_{0}$. Conditions for local stability of equilibrium points are discussed. In the end, simulations are carried out for different situations.
\end{abstract}

Keywords: Endemic; equilibrium points; simulations; SIR model; stability

ABSTRAK

Demam denggi adalah penyakit bawaan vektor virus yang kini berleluasa di lebih 100 buah negara yang melibatkan lebih daripada 2.5 bilion penduduk di seluruh dunia. Sejak kebelakangan ini, demam denggi telah menjadi satu ancaman utama kepada kesihatan awam di Pakistan. Dalam kertas ini, kami menerbitkan formula yang jelas untuk nombor pembiakan $R_{0}$ (parameter epidemiologi yang paling penting) dan kemudian menggunakan data sebenar kes demam denggi daripada hospital berbeza di Lahore (Pakistan) untuk $R_{0}$. Syarat untuk titik keseimbangan kestabilan tempatan dibincangkan. Akhirnya, simulasi dijalankan untuk situasi yang berbeza.

Kata kunci: Endemik; kestabilan; Model SIR; simulasi; titik keseimbangan

\section{INTRODUCTION}

Dengue fever is one of the most rapidly growing mosquitoborne viral infections diseases found in tropical and subtropical regions across the world. According to the present survey of the World Health Organization (WHO), about 50 million cases of dengue occurred in the world every year and over $40 \%$ of the world's population is at risk of dengue (WHO 1997). Dengue fever is caused by four antigenic-ally related but distinct serotypes namely DEN-1, DEN-2, DEN-3 and DEN-4 serotypes. World Health Organization (WHO) estimated that the incidence of dengue fever increased 30-fold between 1960 and 2010.

In Pakistan, the first confirmed dengue hemorrhagic fever outbreak occurred in June 1994, and after that a large number of cases have been reported in different hospitals of the region (Chan et al. 1995). Two serotypes namely DEN-1 and DEN-2 were founded in the sera of children that had undifferentiated fever (Akram et al. 1998). Paul et al. (1998) reported that an outbreak of dengue fever in the Baluchistan province occurred due to co-circulation of DEN-1 and DEN-2. During the year 2005-2006, there was an unprecedented rise in epidemic DHF activity in the country with a large number of cases being reported from Karachi. In year 2006, about 3640 patients with dengue fever (due to DEN-2 and DEN-3 serotypes) were admitted to several hospitals in the country and 40 were reported dead (Khan et al. 2007).
In this paper, we used a model of dengue fever proposed by Derouich et al. (2003). The human population is divided into three subclasses, susceptible, infected and recovered classes, while the vector population is divided into two subclasses, susceptible and infected classes. The model shows that there is a basic reproductive ratio $R_{0}$ that conceptualizes the rate of spread of a dengue disease and determines a threshold: when $R_{0}<1$, a typical infective give rise, on average, to less than one secondary infection and the disease will die out. While, when $R_{0}>1$, a typical infection gives rise, on average, to more than one secondary infection, leading to an epidemic (Hethcote et al. 2000).

The rest of the paper was organized in the following way: First, we formulate the model. In the next two sections we will calculate equilibrium points and discuss their stability. After that we derived an explicit formula for basic reproduction number $R_{0}$. Estimation of $R_{0}$ is given in the last section.

Using Matlab, graph of daily number of cases are plotted against cumulative number of cases for different hospital of Punjab (Pakistan) and force of infection is obtained which is the slope of the graph.

In simulation, we discussed the role of partial vaccination against all four serotypes that can control the second epidemic and particularly the evolution of dengue fever to more severe form dengue hemorrhagic fever. 


\section{A Model of Dengue FeVER}

\section{FIRST EPIDEMIC}

In this model, host population $N_{H}(t)$ is divided into three compartments: Portion of population which is exposed to get infected by dengue virus is termed as susceptible $S_{H}(t)$, a part of the population which is infected $I_{H}(t)$ and people who have recovered $R_{H}(t)$ and vector population $N_{V}(t)$ is divided into two groups of mosquitoes that potentially infected by dengue virus $S_{V}(t)$ and mosquitoes that were infected with dengue virus $I_{V}(t)$. Using block diagram (1), the dynamical system for human (host) and mosquito (vector) population can be modeled by following ordinary differential equations.

$$
\begin{aligned}
& \frac{d S_{H}(t)}{d t}=\lambda N_{H}(t)-\left\{\lambda+p+C_{V H} I_{V}(t) / N_{H}(t)\right\} S_{H}(t) \\
& \frac{d I_{H}(t)}{d t}=C_{V H} S_{H}(t) I_{V}(t) / N_{H}(t)-(\lambda+\gamma) I_{H}(t) \\
& \frac{d R_{H}(t)}{d t}=p S_{H}(t)+\gamma I_{H}(t)-\lambda R_{H}(t) \\
& \frac{d S_{V}(t)}{d t}=\mu N_{V}(t)-\left\{\mu+C_{H V} I_{H}(t) / N_{H}(t)\right\} S_{V}(t) \\
& \frac{d I_{V}(t)}{d t}=C_{H V} S_{V}(t) I_{H}(t) / N_{H}(t)-\mu I_{V}(t),
\end{aligned}
$$

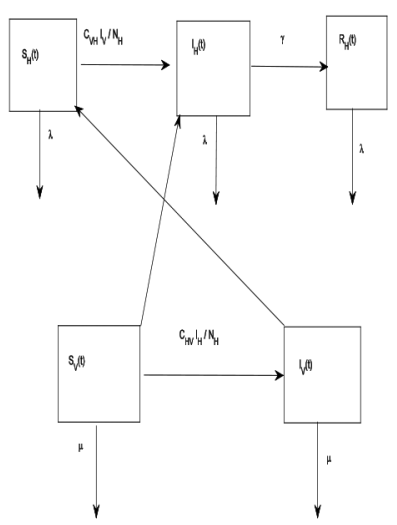

FIGURE 1. Block diagram of SIR dengue fever model (Pakistan). $S_{H} I_{H}, R_{H}$ are susceptible, infected and recovered classes of the host population. $\mathrm{S}_{\mathrm{v}}, \mathrm{I}_{\mathrm{v}}$ is the susceptible, infected classes of the vector population

where $S_{H}(t)+I_{H}(t)+R_{H}(t)=N_{H}(t)$ and $S_{V}(t)+I_{V}(t)=N_{V}(t)$ and $C_{V H}, C_{H V}$ are the contact rate of vector to host and host to vector, respectively. $\gamma$ is the inverse of the duration of host viraemia, $\mu$ is the mortality rate of the vectors, $\lambda$ is the mortality rate of human population and $p$ is the proportion of susceptible humans which is permanently immunized against all four serotypes. Normalizing system of (1) by using following transformations $\frac{S_{H}(t)}{N_{H}(t)}=\hat{S}_{H}(t)$, $\frac{I_{H}(t)}{N_{H}(t)}=\hat{I}_{H}(t), \frac{R_{H}(t)}{N_{H}(t)}=\hat{R}_{H}(t) \frac{S_{V}(t)}{N_{V}(t)}=\hat{S}_{V}(t)$ and $\frac{I_{V}(t)}{N_{V}(t)}=\hat{I}_{V}(t)$ with constraint $\hat{S}_{H}(t)+\hat{I}_{H}(t)+\hat{R}_{H}(t)=1$ and $\hat{S}_{V}(t)+\hat{I}_{V}(t)=1$.

Thus system of (1) takes the form

$$
\begin{aligned}
& \frac{d \hat{S}_{H}(t)}{d t}=\lambda-\left\{\lambda+p+C_{V H} N_{V}(t) \hat{I}_{V}(t) / N_{H}(t)\right\} \hat{S}_{H}(t) \\
& \frac{d \hat{I}_{H}(t)}{d t}=C_{V H} N_{V}(t) \hat{I}_{V}(t) \hat{S}_{H}(t) / N_{H}(t)-(\lambda+\gamma) \hat{I}_{H}(t) \\
& \frac{d \hat{R}_{H}(t)}{d t}=p \hat{S}_{H}(t)+\gamma \hat{I}_{H}(t)-\lambda \hat{R}_{H}(t) \\
& \frac{d \hat{S}_{V}(t)}{d t}=\mu-\left\{\mu+C_{H V} \hat{I}_{H}(t)\right\} \hat{S}_{V}(t) \\
& \frac{d \hat{I}_{V}(t)}{d t}=C_{H V} \hat{I}_{H}(t) \hat{S}_{V}(t)-\mu \hat{I}_{V}(t) .
\end{aligned}
$$

\section{EQUILIBRIUM POINTS}

Equilibrium points of the model are obtain by taking $\frac{d \hat{S}_{H}(t)}{d t}=0, \frac{d \hat{I}_{H}(t)}{d t}=0$ and $\frac{d \hat{I}_{V}(t)}{d t}=0$, i.e.

$$
\begin{aligned}
& \lambda-\left\{\lambda+p+C_{V H} N_{V}(t) \hat{I}_{V}(t) / N_{H}(t)\right\} \hat{S}_{H}(t)=0, \\
& C_{V H} N_{V}(t) \hat{I}_{V}(t) \hat{S}_{H}(t) / N_{H}(t)-(\lambda+\gamma) \hat{I}_{H}(t)=0, \\
& C_{H V} \hat{I}_{H}(t) \hat{S}_{V}(t)-\mu \hat{I}_{V}(t)=0 .
\end{aligned}
$$

As $\hat{S}_{H}(t)+\hat{I}_{H}(t)+\hat{R}_{H}(t)=1$ and $\hat{S}_{V}(t)+\hat{I}_{V}(t)=1$, implies that $\hat{S}_{V}(t)=1-\hat{I}_{V}(t)$. Thus (4) takes the form

$$
C_{H V} \hat{I}_{H}(t)\left\{1-\hat{I}_{V}(t)\right\}-\mu \hat{I}_{V}(t)=0 .
$$

Solving (5) for $\hat{I}_{V}(t)$ and then substituting value of $\hat{I}_{V}(t)$ in (3) we obtain:

$$
\hat{I}_{V}(t)=\frac{\varsigma \hat{I}_{H}(t)}{\varsigma \hat{I}_{H}(t)+1}
$$

and ,

$$
\hat{S}_{H}(t)=\frac{\varsigma \hat{I}_{H}(t)+1}{(1+\hat{p})\left\{(1+\hat{p}) \varsigma+\kappa R_{0}\right\} \hat{I}_{H}(t)},
$$

where $\varsigma=\frac{C_{H V}}{\mu}, \kappa=\frac{\lambda+\gamma}{\lambda}, \hat{p}=\frac{p}{\lambda}$ and $R_{0}=\frac{C_{H V} C_{V H} N_{V}}{\mu(\lambda+\gamma) N_{H}}$.

Solving (3) for $\hat{I}_{H}(t)$ we get

$$
\hat{I}_{H}(t)=\frac{C_{V H} N_{V} \hat{S}_{H}(t) \hat{I}_{V}(t)}{(\lambda+\gamma) N_{H}(t)} .
$$


Substituting values of $\hat{S}_{V}(t)$ and $\hat{I}_{V}(t)$ from (6) and (7) in

(8) we get $\hat{I}_{H}(t)=\frac{C_{V H} N_{V} \hat{S}_{H}(t) \hat{I}_{V}(t)}{(\lambda+\gamma) N_{H}(t)}$ implies that $\hat{I}_{H}(t)=0$ or $\hat{I}_{H}(t)=\frac{R_{0}-1-\hat{p}}{(1+\hat{p}) \varsigma+\kappa R_{0}}$.

Equation (7) gives $V_{1}\left(\frac{1}{1+\hat{p}}, 0,0\right)$ and $V_{2}\left(\stackrel{*}{S_{H}, *_{H}, I_{V}}\right)$, where $\stackrel{*}{S}_{H}(t)=\frac{\varsigma+\kappa}{(1+\hat{p}) \varsigma+\kappa R_{0}}, \quad *_{H}(t)=\frac{R_{0}-1-\hat{p}}{(1+\hat{p}) \varsigma+\kappa R_{0}} \quad$ a $\mathrm{n} \mathrm{d}$ $\stackrel{*}{I}_{V}(t)=\frac{\varsigma\left(R_{0}-1-\hat{p}\right)}{(\varsigma+\kappa) R_{0}}$.

\section{STABILITY FOR EQUILIBRIUM POINTS}

We obtain eigenvalues for equilibrium point by taking $\operatorname{det}\left(J V_{i}-\varsigma_{j} I\right)=0$, where $J V_{i}$, stands for Jacobian matrix for equilibrium points $V_{i}$ for all $i=1 ; 2, I$ is $3 \times 3$ identity matrix and $V_{j}$ for all eigenvalues, which are obtain from left hand side of equations (2), (3) and (5). The Jacobian matrix for equilibrium point $V_{1}\left(\frac{1}{1+\hat{p}}, 0,0\right)$ is $J_{V 1}=\left[\begin{array}{ccc}-\lambda(1+\hat{p}) & 0 & \frac{-C_{V H}}{1+\hat{p}} \\ 0 & -(\lambda+\gamma) & \frac{C_{V H}}{1+\hat{p}} \\ - & C_{H V} & -\mu\end{array}\right]$, the characteristic equation for Jacobian matrix at $V_{1}\left(\frac{1}{1+\hat{p}}, 0,0\right)$ is $\{\zeta+\lambda(1+\hat{p})\}\{(\zeta+$ $\left.\mu)(\zeta+\lambda+\gamma)-C_{V H} C_{H V} /(1+\hat{p})\right\}=0$.

One eigenvalue is $\zeta_{1}=-\lambda(1+\hat{p})$ and the remaining eigenvalues are obtained by solving the equation $\zeta^{2}+(\lambda \kappa$ $+\mu) \zeta+\lambda \mu \kappa\left\{1-\frac{R_{0}}{1+\hat{p}}\right\}=0$. These two eigenvalues have negative real parts if the given equation satisfoes the Routh-Hurwitz criteria (Robert 1997) for stability i.e., $\lambda \kappa$ $+\mu>0$ and $\left\{1-\frac{R_{0}}{1+\hat{p}}\right\}>0$, which is possible only if $R_{0}<$ $1+\hat{p}$. Thus the equilibrium point $V_{1}\left(\frac{1}{1+\hat{p}}, 0,0\right)$ is locally asymptotically stable. For the second equilibrium point

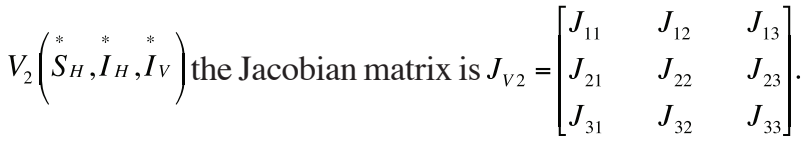
where $J_{11}=-\lambda\left[\frac{(1+\hat{p}) \varsigma+\kappa R_{0}}{\varsigma+\kappa}\right], J_{12}=0, J_{13}=-C_{V H}$ $\left[\frac{\varsigma+\kappa}{\varsigma(1+\hat{p})+\kappa R_{0}}\right], J_{21}=\frac{\lambda \kappa\left(R_{0}-1-\hat{p}\right)}{\varsigma+\kappa}, J_{23}=C_{V H}\left[\frac{\varsigma+\kappa}{\varsigma(1+\hat{p})+\kappa R_{0}}\right]$, $J_{31}=0, J_{32}=C_{H V}\left[\frac{\kappa R_{0}+\varsigma(1+\hat{p})}{(\varsigma+\kappa) R_{0}}\right], J_{33}=-\left[\frac{\mu R_{0}+(\kappa+\varsigma)}{(1+\hat{p}) \varsigma+\kappa R_{0}}\right]$. The characteristic equation is $P(\xi)=\zeta^{3}+A \xi^{2}+B \zeta+C$, where $A=-\operatorname{trac}\left(J V_{2}\right), B=\operatorname{det}\left[\begin{array}{ll}J_{11} & J_{13} \\ J_{21} & J_{22}\end{array}\right]+\operatorname{det}\left[\begin{array}{ll}J_{11} & J_{13} \\ J_{31} & J_{33}\end{array}\right]+$ $\operatorname{det}\left[\begin{array}{ll}J_{22} & J_{23} \\ J_{32} & J_{33}\end{array}\right], C=-\operatorname{det}\left(J V_{2}\right)$

$A=\lambda\left[\frac{(1+\hat{p}) \varsigma+\kappa R_{0}}{\varsigma+\kappa}\right]+\lambda \kappa+\left[\frac{\mu R_{0}(\kappa+\varsigma)}{(1+\hat{p}) \varsigma+\kappa R_{0}}\right]$,

$B=\lambda^{2} \kappa\left[\frac{(1+\hat{p}) \varsigma+\kappa R_{0}}{\varsigma+\kappa}\right]+\lambda \mu R_{0}+\frac{\lambda \kappa \mu \varsigma\left(R_{0}-1-\hat{p}\right)}{(1+\hat{p}) \varsigma+\kappa R_{0}}$,

$C=\lambda^{2} \kappa \mu\left(R_{0}-1-\hat{p}\right)$.

The characteristic equation has three eigenvalues $\zeta_{1}$, $\zeta_{2}$ and $\zeta_{3}$. These eigenvalues will have negative real part if they satisfy Routh-Hurwitz criteria (Robert 1997) for stability i.e., $A>0, C>0$ and $A B>C$. Clearly $A>0, C>0$ and $A B>C$, if $R_{0}>2+\hat{p}$. Thus the endemic equilibrium state $V_{2}\left(S_{H}^{*}, I_{H}^{*}, I_{V}^{*}\right)$ is locally asymptotically stable for $R_{0}>$ $1+\hat{p}$, where $R_{0}$ (basic reproductive number) is the number of secondary cases when an infected person is introduced in a totally susceptible population.

\section{PRINCIPLE OF HERD IMMUNITY}

Herd immunity in a host population is achieved by vaccination of susceptible people. Here in this model $R_{0} \leq 1+\hat{p}$ i.e. $\lambda\left(R_{0}-1\right) \leq p$ represents the principle of herd immunity.

\section{SECOND EPIDEMIC}

In this case, we assumed that a fraction of susceptible host population is globally immunized against all four serotypes (i.e. DEN-1, DEN-2, DEN-3 and DEN-4) or partially immunized against one, two or three viruses. The onset of second infection of immunized or removed class with another virus leads to DHF (Dengue hemorrhagic fever). In this section we concentrate only on the removed $R_{H}(t)$ of first epidemic who are now exposed to the second epidemic where new population is $N_{H}(t)$. Thus dynamical equations for host and vector population are,

$$
\begin{aligned}
& \frac{d \stackrel{\circ}{S}_{H}(t)}{d t}=\lambda \stackrel{\circ}{N}_{H}(t)-\left\{\lambda+p+\stackrel{\circ}{C}_{V H} I_{V}(t) / N_{H}(t)\right\} \stackrel{\circ}{S}_{H}(t) \\
& \frac{d \stackrel{\circ}{R}_{H}(t)}{d t}=p \stackrel{\circ}{S}_{H}(t)+\gamma \stackrel{\circ}{I}_{H}(t)-\lambda \stackrel{\circ}{R}_{H}(t) \\
& \frac{d \stackrel{\circ}{I}_{H}(t)}{d t}=\stackrel{\circ}{C}_{V H} \stackrel{\circ}{S}_{H}(t) I_{V}(t) / N_{H}(t)-(\lambda+\gamma) \dot{\circ}_{H}(t) \\
& \frac{d S_{V}(t)}{d t}=\mu N_{V}(t)-\left\{\mu+\stackrel{\circ}{C}_{H V} \stackrel{\circ}{I}_{H}(t) / \stackrel{\circ}{N}_{H}(t)\right\} S_{V}(t) \\
& \frac{d I_{V}(t)}{d t}=\stackrel{\circ}{C}_{H V} S_{V}(t) \stackrel{\circ}{I}_{H}(t) / \stackrel{\circ}{N}_{H}(t)-\mu I_{V}(t) .
\end{aligned}
$$

With condition $\stackrel{\circ}{S}_{H}(t)+\stackrel{\circ}{I}_{H}(t)+\stackrel{\circ}{R}_{H}(t)=\stackrel{\circ}{N}_{H}(t)$, where $\stackrel{\circ}{C}_{V H}$, $C_{H V}$ are the contact rate of vector to human and human 
to vector in the second epidemic, respectively. Similar to the first epidemic, the equilibrium points of second epidemic are $V_{1}\left(\frac{1}{1+\hat{p}}, 0,0\right)$ and $V_{2}\left(\stackrel{*}{S}_{H}, \stackrel{*}{I_{H}}, \stackrel{*}{I_{V}}\right)$, respectively, wh e re $\quad \stackrel{*}{S}_{H}(t)=\frac{\chi+\kappa}{(1+\hat{p}) \chi+\kappa R_{0}}, \quad \stackrel{*}{I}_{H}(t)=\frac{R_{0}-1-\hat{p}}{(1+\hat{p}) \chi+\kappa R_{0}}$, $\stackrel{*}{I}_{V}(t)=\frac{\chi\left(R_{0}-1-\hat{p}\right)}{(\chi+\kappa) R_{0}}, \chi=\frac{\stackrel{C}{H V}_{H V}^{*}}{\mu}$ and $R_{0}=\frac{\stackrel{\circ}{C}_{H V} \stackrel{\circ}{C}_{V H} N_{V}}{\mu(\lambda+\gamma) \stackrel{\circ}{N}_{H}}$. The equilibrium point $V_{1}\left(\frac{1}{1+\hat{p}}, 0,0\right)$ is globally asymptotically stable when $R_{0}<1+\hat{p}$. While $V_{2}\left(\stackrel{*}{S_{H}, \stackrel{*}{I}_{H},{ }^{*} I_{V}}\right)$ is locally asymptotically stable if $R_{0}>1+\hat{p}$.

\section{DERIVATION OF $R_{0}$ FROM THE MODEL}

Initially, in the case of epidemic, the infected number of accumulative cases can be vary as $I_{H}(t) \propto \exp (\Lambda t)$, and $I_{V}(t) \propto \exp (\Lambda t)$, implies that:

$$
I_{H}(t)=H_{0} \exp (\Lambda t) \text { and } I_{V}(t)=V_{0} \exp (\Lambda t),
$$

where ' $\Lambda$ ' is the force of infection, $H_{0}$ is the initial proportion of susceptible hosts; and is the initial proportion of susceptible vectors. Here $H_{0}$ and $V_{0}$ are some constants. Suppose that non-susceptible humans and vectors are negligible. So that $S_{H}(t) \approx N_{H}(t)$ and $S_{V}(t) \approx N_{V}(t) . R_{0}$ is derived from the equations as:

Differentiating (9) with respect to $t$ we obtained:

$$
\frac{d I_{H}(t)}{d t}=H_{0} \Lambda \exp \Lambda t \text {, and } \frac{d I_{V}(t)}{d t}=V_{0} \Lambda \exp \Lambda t
$$

substituting (10) in (2) and (5) we get

$$
C_{V H} V_{0} \exp \Lambda t-(\lambda+\gamma) H_{0} \exp \Lambda t=H_{0} \Lambda \exp \Lambda t,
$$

and

$$
C_{H V} V_{0} \exp (\Lambda t) N_{V} / H_{0} \exp \Lambda t=V_{0} \Lambda \exp \Lambda t,
$$

simplifying (11) and (12) we get $C_{V H} V_{0}-(\lambda+\gamma) H_{0}=H_{0} \Lambda$,

$C_{H V} H_{0} N_{V} / N_{H}-\mu V_{0}=V_{0} \Lambda$, which gives

$C_{H V} V_{0}-(\lambda+\gamma+\Lambda) H_{0}=0$,

$C_{H V} H_{0} N_{V} / N_{H}-(\mu+\Lambda) V_{0}=0$, solving above equations we have $C_{H V} C_{V H} N_{V} / N_{H}=(\mu+\Lambda)(\lambda+\gamma+\Lambda)$,

implies that $\frac{C_{H V} C_{V H} N_{V}}{\mu(\lambda+\gamma) N_{H}}=\left(1+\frac{\Lambda}{\lambda+\gamma}\right)\left(1+\frac{\Lambda}{\mu}\right)$.

Using the idea of Degalliar et al. (2005), the left hand side of (14) is the basic reproductive number $R_{0}$. This can be seen as follows:
The contact rate of vector to Human is $C_{V H}$ times per unit of time. Assumed that $(\lambda+\gamma)^{-1}$ is the average duration of infection. The contact rate of human to vector is $C_{H V}$ per unit of time. An infected body is introduced in a totally susceptible population which will produce $\frac{C_{H V} C_{V H} N_{V}}{(\lambda+\gamma) N_{H}}$ infected mosquitoes. Assumed that $\frac{1}{\mu}$ be the mean life expectancy of the mosquitoes (Macdonald 1952). Then the number of infected mosquitoes will produce $\frac{C_{H V} C_{V H} N_{V}}{(\lambda+\gamma) N_{H}}$ human secondary infections. Thus from (14) we obtained $R_{0}$ as:

$$
R_{0}=\left(1+\frac{\Lambda}{\lambda+\gamma}\right)\left(1+\frac{\Lambda}{\mu}\right)
$$

\section{ESTIMATION OF $R_{0}$}

Four parameters are used in the estimation of reproduction number $R_{0}=\left(1+\frac{\Lambda}{\lambda+\gamma}\right)\left(1+\frac{\Lambda}{\mu}\right)$. The parameter $\lambda=0: 0000391$ per day corresponds to the actual life estimating of 70 years for human (host) (Pongsumpun 2008), recovery rate $\frac{1}{\gamma}$ of host is estimated as 6 days (Mcbride et al. 2000). The other parameter mortality rate of vectors $\mu$ depend on external temperature, following Focks et al. (1993), Favier et al. (2006) modeled them by the following equations:

$$
\begin{aligned}
& \mu=-\ln \left[0.9 \mu_{1}(T) \mu_{2}(P v d)\right], \\
& \mu_{1}(T)=\left[\begin{array}{ll}
(T-5) / 5, & T \in(5,10) \\
1, & T \in[10,41] \\
1-(T-41) / 2, & T \in(41,43) \\
0, & \text { otherwise }
\end{array}\right],
\end{aligned}
$$

$$
\begin{aligned}
P v d & =6.11 \exp \{17.3(T / T+237.3)\}(1-R H / 100), \\
\mu_{2}(P v d) & =\left[\begin{array}{ll}
1, & \text { below } 10 \\
1-0.4(P v d-10) / 20, & P v d \in[10,30] \\
0.6, & \text { above } 30
\end{array}\right],
\end{aligned}
$$

where $\mathrm{T}$ is the temperature in degrees Celsius and Pvd is vapour pressure in mbar.

We collected metrological data from the metrological department of Punjab province during the epidemic year 2010-2011. Data include vapour pressure, relative humidity and temperature $\left(\mathrm{C}^{0}\right)$ of Lahore which is used in the estimation of mortality rate of vector population. The average yearly temperature of Lahore is $24.5 \mathrm{C}^{0}$. Graph of temperature of Lahore against months is shown in Figure 2.

We also collected dengue fever data during the year 2010-2011 from the directorate of general health Punjab, 
TABLE 1. Monthly weather report of Lahore (Pakistan)

\begin{tabular}{lccc}
\hline Month & V.P $(\mathrm{mb})$ & $\mathrm{RH}(\%)$ & $\mathrm{Temp}\left(\mathrm{C}^{0}\right)$ \\
\hline January & 9.2 & 86.0 & 13.2 \\
February & 9.9 & 79.7 & 15.7 \\
March & 12.5 & 75.3 & 20.5 \\
April & 14.0 & 62.9 & 27.0 \\
May & 15.4 & 53.3 & 31.7 \\
June & 21.8 & 61.7 & 33.6 \\
July & 29.8 & 81.7 & 31.3 \\
August & 31.0 & 85.8 & 30.7 \\
September & 25.5 & 82.5 & 29.6 \\
October & 17.5 & 80.1 & 25.7 \\
November & 13.2 & 84.6 & 20.1 \\
December & 11.5 & 86.9 & 14.8 \\
Average & 15.5 & 76.7 & 24.5 \\
\hline
\end{tabular}

which is used in the estimation of basic reproductive number $R_{0}$.

\section{DISCUSSION}

In this paper, we obtained the basic reproduction number $\left(R_{0}\right)$, by using two methods. In the first method, $R_{0}$ obtained from equilibrium points of the model for dengue fever (previous section) is $R_{0}=\frac{C_{H V} C_{V H} N_{V}}{\mu(\lambda+\gamma) N_{H}}$. In the second method we derived $R_{0}$ from the model, when initially, the infected number of accumulative cases of both human and mosquito population vary exponentially is $R_{0}=\left(1+\frac{A}{\lambda+\gamma}\right)\left(1+\frac{A}{\mu}\right)$. Reproduction number $R_{0}$, depends on $C_{H V}$ (contact rate of human to vector) and $C_{V H}$ (contact rate of vector to human). $R_{0}$, increases with the increase in $C_{H V}$ and $C_{V H}$, while $o$ ther parameter values are kept fixed in the estimation of $R_{0}$. Graph of linear fit of declared daily number of cases against cumulative number of cases for Jinnah hospital, Mayo hospital, Institute of Public Health, Lahore hospital and Sir Ganga Ram hospital of Lahore (Pakistan) are drawn in Figure 3(a)-3(e). Slope of graph of linear fit is the force of infection $(\Lambda)$. In Table 2, we estimated the values of Reproduction number $R_{0}$ which gave $R_{0}>1$ means disease is epidemic in the region.

Two equilibrium points, disease free equilibrium point $V_{1}\left(\frac{1}{1+\hat{p}}, 0,0\right)$ and endemic equilibrium state, $V_{2}\left(\stackrel{*}{S_{H}, \stackrel{*}{I}_{H}, I_{V}}\right)$ are obtained from the model. The stability of both equilibrium points is discussed. The equilibrium point $V_{1}\left(\frac{1}{1+\hat{p}}, 0,0\right)$ is locally asymptotically stable when $R_{0}<1$ $+\hat{p}$, while $V_{2}\left(\stackrel{*}{S_{H},{ }^{*}}{ }_{H},{ }^{*} I_{V}\right) ;$ the endemic equilibrium state is

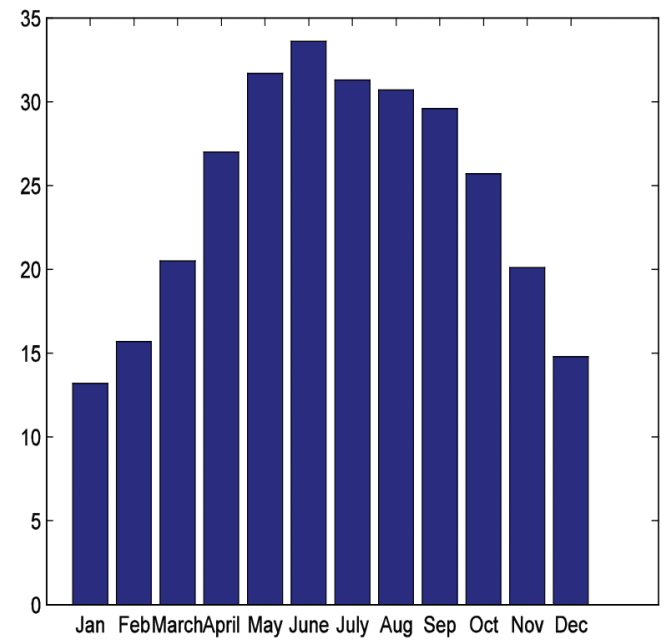

FIGURE 2. Monthly temperature of Lahore (Pakistan) is plotted along $\mathrm{y}$-axis and months along $\mathrm{x}$-axis

locally asymptotically stable when $R_{0}>1+\hat{p}$ where $R_{0}$ (the basic reproduction number) is the strength of epidemic.

In simulation, Figure 4(a)-4(d) shows the infected proportion of human population against time when $p=$ $0, p=0: 25, p=0: 75$ and $p=0.85$, Figure 5(a)-5(c) shows the numerical solutions for $R_{0}<1$ and asymptotically converge to the disease free equilibrium state $V_{1}\left(\frac{1}{1+\hat{p}}, 0,0\right)$ when $p=0$ implies $\hat{p}=0$. The susceptible proportion tends to be 1 , since in the disease free equilibrium state, the whole population is healthy. The infected proportion of both human and vector converges to zero, which shows that population is disease free. Figure 6(a)-6(c) shows numerical solutions for $R_{0}>1$ and oscillate to the endemic equilibrium state $V_{2}(0.0364 ; 0.000527 ; 0.00276)$.

\section{CONCLUSION}

Dynamical analysis of the model shows that the existence of two equilibrium points. One is the disease-free equilibrium point which is locally asymptotically stable when $R_{0}<1$. The second equilibrium point is endemic equilibrium point which is locally asymptotically stable if $R_{0}>1$. We obtained the basic reproduction number and then estimated its value by using data of different hospitals in Lahore (Pakistan). On the basis of these estimations we conclude that Dengue is epidemic in Lahore and serious actions must be taken to control the dengue disease. Otherwise it may spread to other parts of the country. It means that in year (2010-2011) the Dengue disease is an epidemic in Lahore (Pakistan).

In the absence of dengue vaccine, public health control depends on the reduction of reproduction number $R_{0}$, which is reduced by decreasing the parameters $C_{H V}$ and $C_{V H}$. This can be done by reducing the vector breeding sites, decreasing the life span of vector, reducing the mosquito biting rate by quarantine and by targeted spray on larval places. 


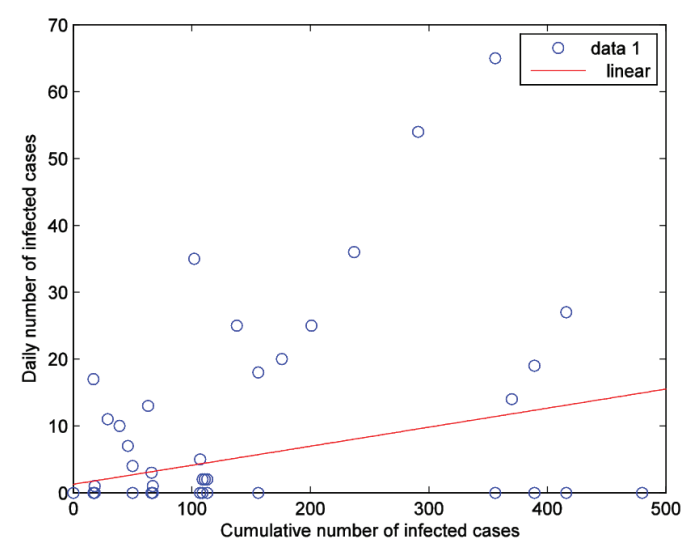

(a)

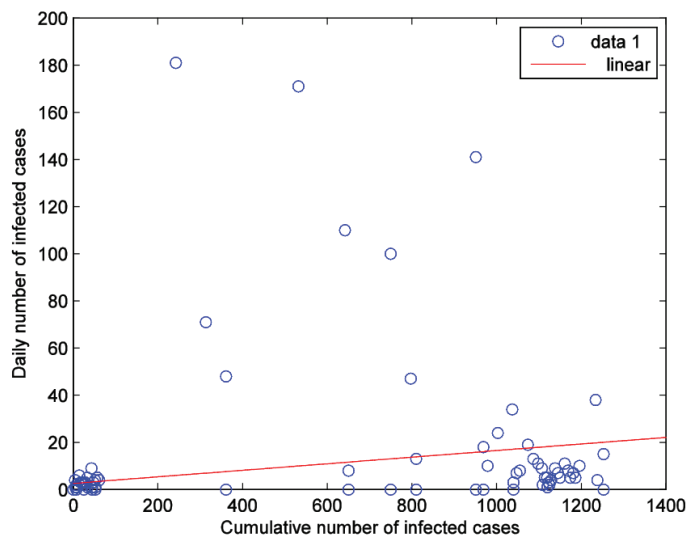

(c)

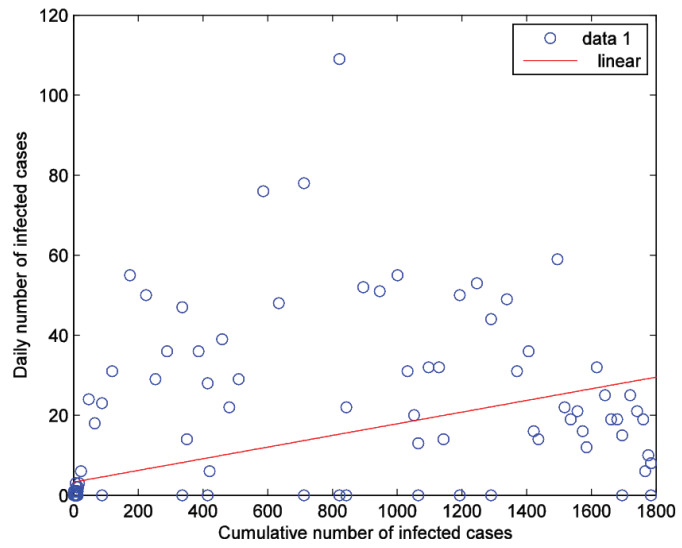

(b)

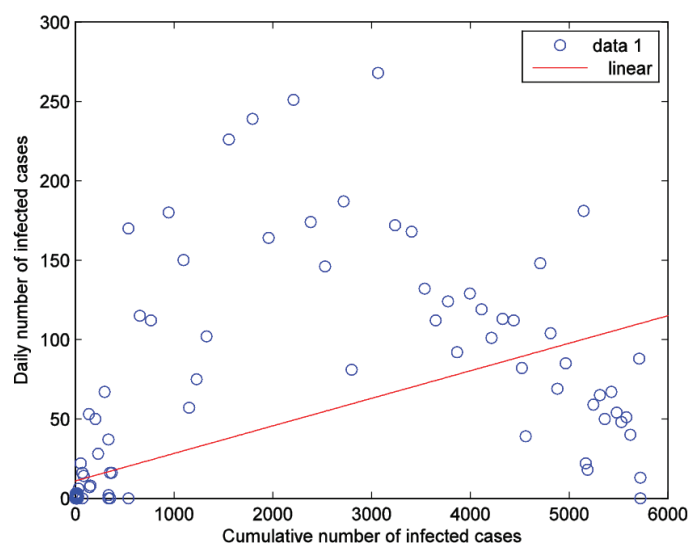

(d)

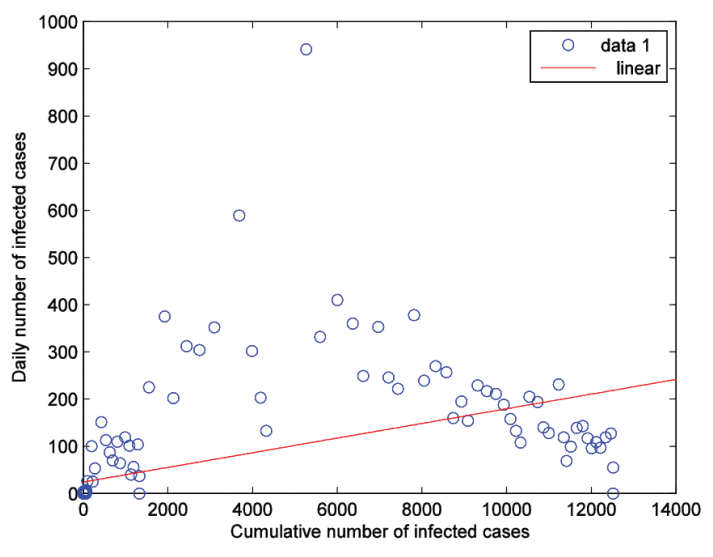

(e)

FIGURE 3. Graph of daily number of cases plotted against cumulative number of cases for different hospitals of Lahore (Pakistan). The force of infection $(\Lambda)$ is the slope of the graph and is computed by least square linear fit to the data, (a) Jinnah hospital data,

(b) IPH data, (c) Sir Ganga Ram hospital data, (d) Mayo hospital data and (e) Lahore Hospital data

TABLE 2. Estimation of $R_{0}$ for five Epidemics (EP) in different hospitals of Lahore (Pakistan)

\begin{tabular}{lccccc}
\hline EP & $\Lambda$ & $\mathrm{T}\left(\mathrm{C}^{0}\right)$ & $\mathrm{RH}(\%)$ & $\mu$ & $R_{0}$ \\
\hline J H & 0.028 & 24.5 & 76.7 & 0.21 & 1.329 \\
MH & 0.017 & 24.5 & 76.7 & 0.21 & 1.195 \\
IPH & 0.015 & 24.5 & 76.7 & 0.21 & 1.162 \\
LH & 0.015 & 24.5 & 76.7 & 0.21 & 1.174 \\
GRH & 0.014 & 24.5 & 76.7 & 0.21 & 1.155 \\
\hline
\end{tabular}

JH (Jinnah hospital), MH (Mayo hospital), IPH (Institute of public health), LH (Lahore hospital), and GRH (Sir Ganga Ram hospital) 


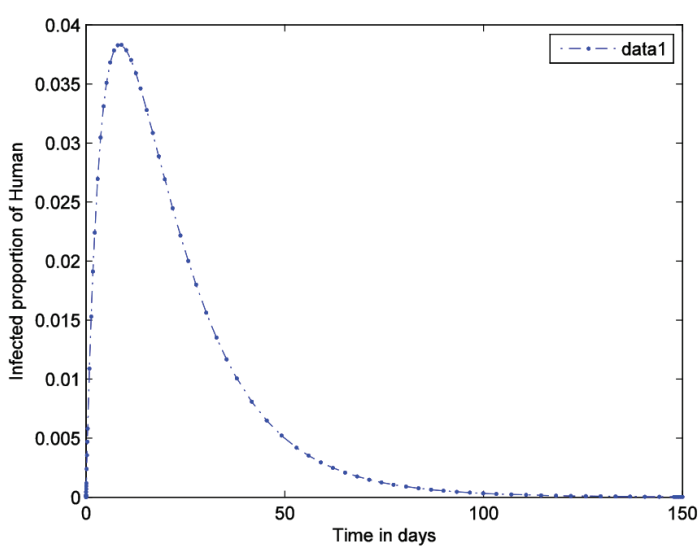

(a)

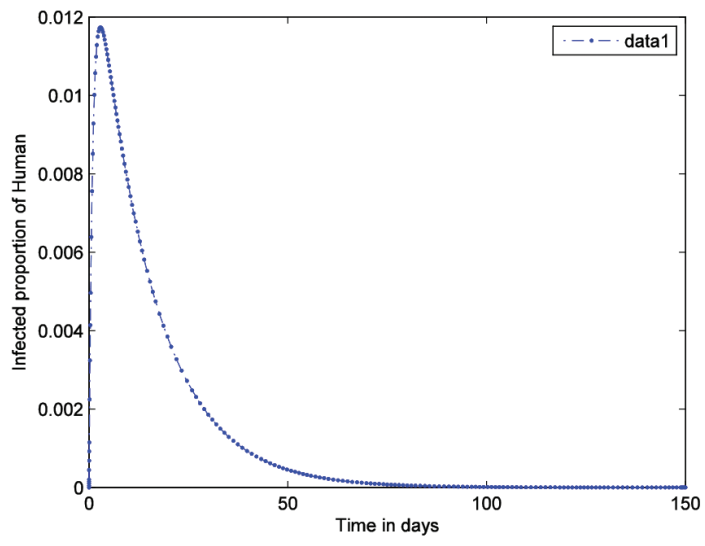

(c)

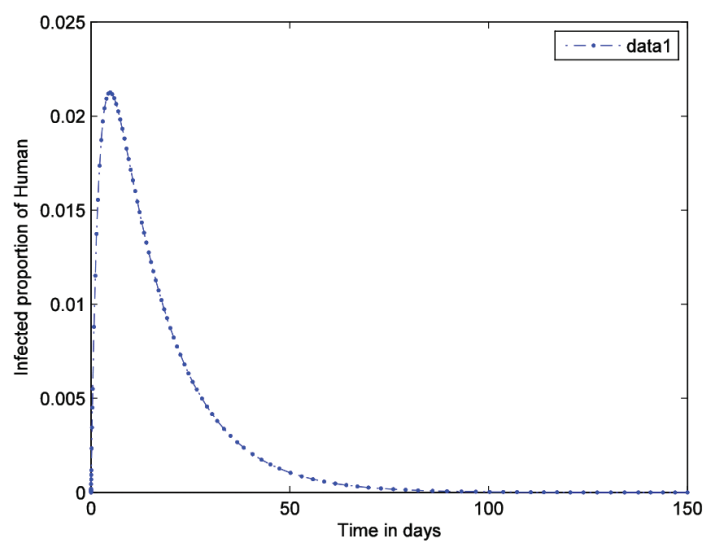

(b)

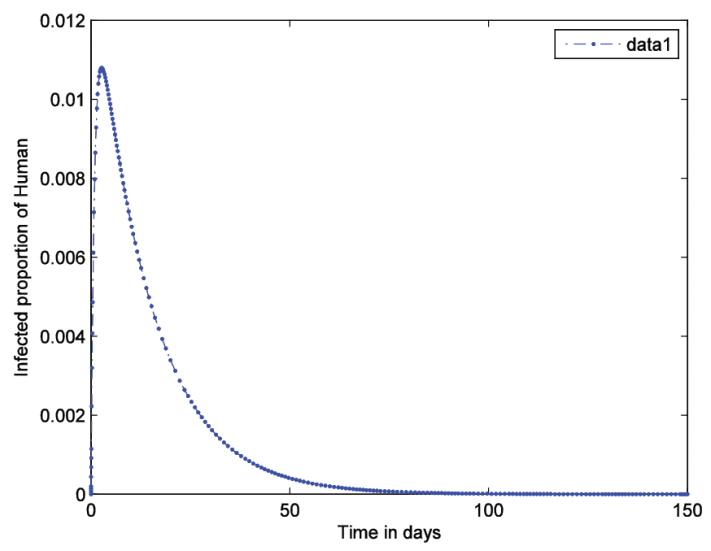

(d)

FIGURE 4. The role of vaccination in the infected host population, (a) Infectd proportion of human versus time/days when $p=0$ i. e, without vaccination, (b) Infected proportion of human versus time/days when $p=0.25$, (c) Infected proportion of human versus time versus time/days when $p=0.75$ and (d) Infected proportion of human versus time / days when $p=0.85$

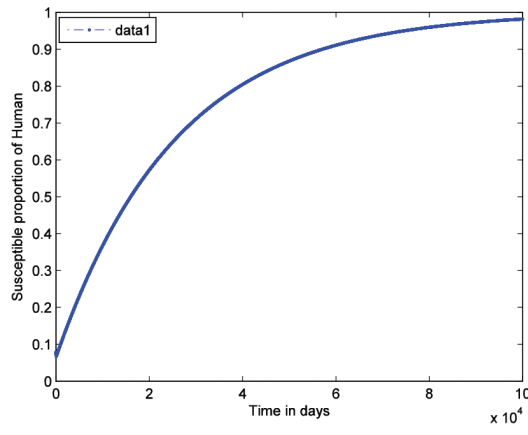

(a)

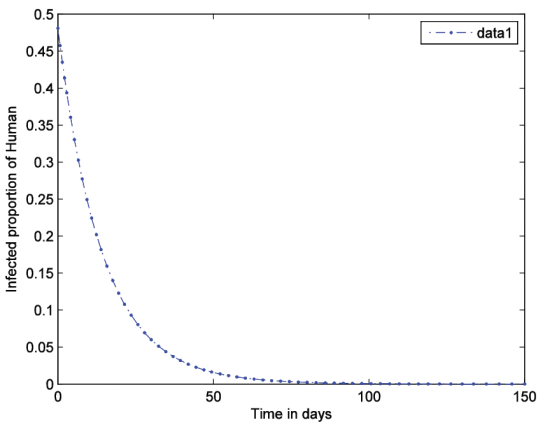

(b)

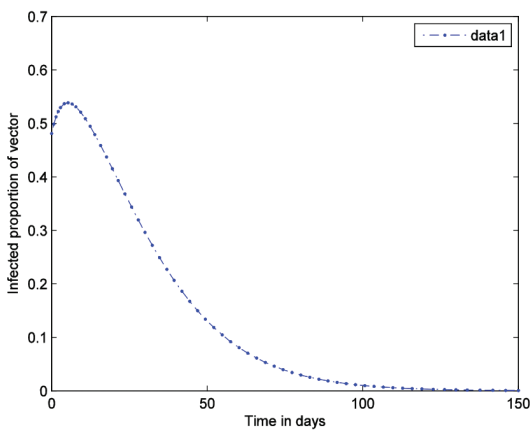

(c)

Here $\lambda=0: 0000391$ (fixed), $\gamma=1 / 14=0: 07142857$ (fixed), $\mu=1 / 14=0: 07142857$ (fixed), $C_{H V}=0: 25, C_{V H}=0: 02$, and $p=0$

FIGURE 5. The parameters values are taken from (Pongsumpun 2008), (a) Susceptible proportion of human versus time/days, (b) Infected proportion of human versus time/days and (c) Infected proportion of vector versus time/days 


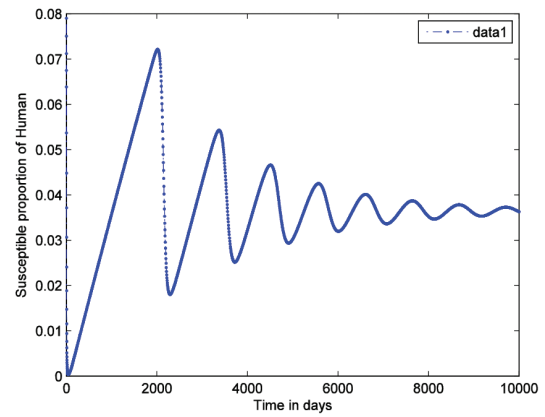

(a)

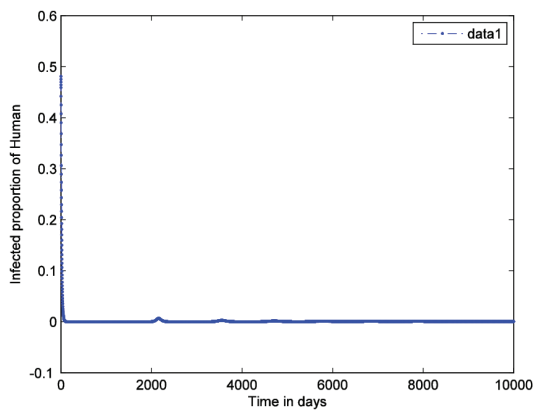

(b)

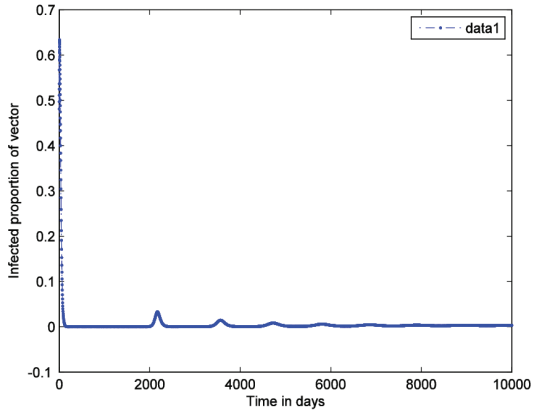

(c)

Here $\lambda=0: 0000391$ (fixed), $\mu=1 / 14=0: 07142857$ (fixed), $\gamma=1 / 14=0: 07142857$ (fixed), $C_{H V}=0: 375, C_{V H}=0: 75$ and $p=0$

FIGURE 6. The parameters values are taken from (Pongsumpun 2008), (a) Susceptible proportion of human, (b) Infected proportion of human versus time/days versus time/days and (c) Infected proportion of vector versus time/days

\section{ACKNOWLEDGMENTS}

We are thankful to Dr Mubashir Director, Directorate of General Health Lahore (Punjab), Dr Jamal Akbar Orakzai Health Directorate (K. P. K) and Dr Muhammad Sardar Hayat W.H.O (K. P. K) for their utmost cooperation with the data collection.

\section{REFERENCES}

Akram, D.S., Igarashi, A. \& Takasu, T. 1998. Dengue virus infection among children with undifferentiated fever in Karachi. Indian J. Pediatr. 65: 735-740.

Chan, Y.C., Salahuddin, N.I., Khan, J., Tan, H.C. \& Seah, C.L. 1995. Dengue haemorrhagic fever outbreak in Karachi, Pakistan. Trans R. Soc. Trop. Med. Hyg. 89: 619-620.

Degallier, N., Favier, C., Boulanger, J.P., Menkes, C.E. \& Oliveira, C. 2005. Unenouvelle methode d'estimation du taux de reproduction des maladies $\left(R_{0}\right)$ : application a l'etude des epidemies de Dengue dans le District Federal, Bresil. Environnement, Risques et Sante 4: 131-135.

Derouich, M., Boutayeb, A. \& Twizell, E.H. 2003. A model of dengue fever. Biomedical Engineering Online 2(1): 4.

Favier, C., Degallier, N. \& Rosa-Freitas, M.G. 2006. Early determination of the reproductive number for vector-borne diseases: The case of dengue in Brazil. Tropical Medicine and International Health 3: 332-340.

Focks, D.A., Haile, D.G., Daniels, E. \& Mount, G.A. 1993. Dynamic life table model for Aedes aegypti (Diptera: Culicidae): Analysis of the literature and model development. Journal of Medical Entomology 30: 1003-1017.
Hethcote, H.W. 2000. The mathematics of infectious diseases. SIAM Review 42(4): 599-653.

Khan, E., Siddiqui, J., Shakoor, S., Mehraj, V., Jamil, B. \& Hasan, R. 2007. Dengue outbreak in Karachi, Pakistan, experience at a tertiary care center. Trans R. Soc. Trop. Med. Hyg. 101: 1114-1119.

Mcbride, W.J. \& Bielefeldt-Ohmann, H. 2000. Dengue viral infections: Pathogenesis and epidemiology. Microbes and Infection 2: 1041-1050.

Paul, R.E., Patel, A.Y., Mirza, S., Fisher-Hoch, S.P. \& Luby, S.P. 1998. Expansion of epidemic dengue viral infections to Pakistan. Int. J. Infect. Dis. 2: 197-201.

Pongsumpun, P. 2008. Mathematical model of dengue disease with the incubation period of virus. World Academy of Science, Engineering and Technology. p. 44.

Robert, M. 1997. Stability and Complexity in Model Ecosystems. New Jersey: Princeton University Press.

World Health Organization. 1997. Dengue Haemorrhagic Fever: Diagnosis, Treatment, Prevention and Control. Geneva.

Department of Basic Sciences

University of Engineering of Technology Peshawar

Pakistan

*Corresponding author; email: noor2knoor@gmail.com

Received: 8 September 2013

Accepted: 15 June 2015 